\title{
Effect of Changing Strain Rate on Flow Stress during Hot Deformation of Type 316L Stainless Steel
}

\author{
M.F. Abbod ${ }^{1}$, C.M. Sellars ${ }^{2 *}$, A. Tanaka ${ }^{3}$, D.A. Linkens ${ }^{4 *}$, M. Mahfouf ${ }^{4 *}$ \\ * IMMPETUS \\ Institute for Microstructural and Mechanical Process Engineering: The University of \\ Sheffield (UK) \\ ${ }^{1}$ School of Engineering and Design, Brunel University, Uxbridge UB8 3PH, UK \\ ${ }^{2}$ Department of Engineering Materials, The University of Sheffield, Mappin Street, \\ Sheffield S1 3JD, UK \\ ${ }^{3}$ Nippon Steel Corporation, 2-6-3 Otemachi, Chiyoda-ku, Tokyo 100-8071, Japan. \\ ${ }^{4}$ Department of Automatic Control and System Engineering, The University of \\ Sheffield, Mappin Street, Sheffield S1 3JD, UK
}

\begin{abstract}
In industrial rolling, changes in strain rate and temperature occur with strain during passes, and between one pass and the next. Plane strain compression testing has been used with ramped changes in strain rate during deformation, and with changes in strain rate between two deformations to study their effects on flow stress. No systematic deviations from a mechanical equation of state were found for ramped increase or decrease in strain rate, even at the highest experimental ramping rates. In the two deformation tests, static recovery between deformations reduced the initial flow stress below the value for an equation of state by an amount dependent on time. The reduction was increased when strain rate was increased for the second deformation, and the strain interval required to re-establish the equation of state flow stress is uniquely related to the initial reduction in stress.
\end{abstract}

Keywords: 316L stainless steel, plane strain compression tests, strain rate changes, equation-of-state flow stress, transient flow stress. 


\section{Introduction}

During hot deformation, the flow stress at a specific strain for most alloys is related to

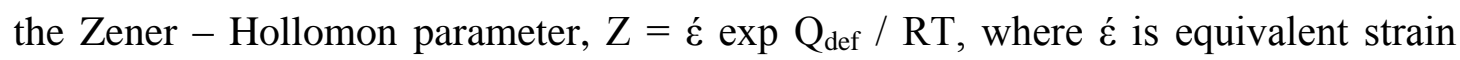
rate, $\mathrm{Q}_{\mathrm{def}}$ is a constant activation energy for deformation, $\mathrm{R}$ is the gas constant and $\mathrm{T}$ is the absolute temperature. The majority of laboratory tests used to obtain constitutive equations for flow stress are carried out at nominally constant $\mathrm{Z}$, but during industrial rolling there are major changes of strain rate and temperature, which lead to changing conditions of $\mathrm{Z}$. These are essentially of two types: (1) between passes, when no deformation is taking place, and (2) during passes, when $\mathrm{Z}$ changes with strain. Between passes, the material is undergoing microstructural changes by static recovery and, possibly, by static recrystallisation, and changes in $\mathrm{Z}$ between two passes arise from increase in roll speed in tandem mills and from decrease in temperature, which may be particularly significant when accelerated cooling is applied. Both changes lead to an increase in $\mathrm{Z}$ between the two passes. During a rolling pass, when dynamic microstructural changes are taking place, strain rate rises to a maximum value and then falls to zero at exit. This may be accompanied by a rise in temperature in the bulk of the stock, or by a severe chilling near the surfaces in contact with the rolls. Thus $\mathrm{Z}$ may increase or decrease with increasing strain at rates that depend on the specific rolling conditions and the location within the stock of the region of interest.

For finite element modelling of rolling, it is usually assumed that the constitutive equations for flow stress determined from test results at nearly constant $\mathrm{Z}$ can be applied as mechanical equations of state to changing $\mathrm{Z}$ conditions, i.e. the flow stress at any strain is assumed to be a function only of the instantaneous value of Z. For some materials, such as ferritic stainless steel [1,2], austenitic stainless steel [3], and aluminium $-1 \% \operatorname{Mg}[2,4,5]$ tests with ramped changes in strain rate have shown this to be a realistic assumption, whereas for other materials, such a pure $\alpha$-iron [6], aluminium [2] and copper [6] there are systematic deviations, which increase in magnitude with increase in rate of change of $\mathrm{Z}$ with strain. The deviation can be expressed in terms of $\mathrm{H}[3]$, where $\mathrm{H}$ is conveniently defined as

$$
\mathrm{H}=\mathrm{d} \log \mathrm{Z} / \mathrm{d} \varepsilon
$$


In interrupted, two deformation, tests there is always some static recovery between passes, which reduces the initial flow stress below the value expected for the accumulated strain, when $\mathrm{Z}$ is the same for each pass. However, the equation of state value is usually reached after a relatively small strain compared with the total strain of the next pass [7]. If $\mathrm{Z}$ is increased or decreased "instantaneously" during deformation, the initial flow stress at the new $\mathrm{Z}$ differs significantly from the value expected from a mechanical equation of state, and the strain interval for the transients in flow stress depend on the material composition, and may be relatively large [3, $8-10]$. The situation is more complicated if either static recrystallisation occurs between passes [7], or dynamic recrystallisation takes place during the passes [3]. The objective of the present paper is to study the flow stress of Type $316 \mathrm{~L}$ stainless steel when type (1) and type (2) change in $\mathrm{Z}$ conditions are imposed at temperatures, strain rates and interpass times when neither static nor dynamic recrystallisation take place.

\section{Experimental Procedure}

Plane strain compression tests were carried out on two batches of steel. The Batch 1 steel, used for the type (1) tests, is of analysis shown in Table 1, and was experimentally melted and cast into $72 \mathrm{~mm}$ square ingots. These were annealed for 2 hrs at $1200{ }^{\circ} \mathrm{C}$ to eliminate $\delta$-ferrite, then hot rolled to bars of $10 \mathrm{~mm}$ thickness and $55 \mathrm{~mm}$ width to cut into $60 \mathrm{~mm}$ lengths for specimens. The final pass at $1100{ }^{\circ} \mathrm{C}$, and subsequent annealing at $1100^{\circ} \mathrm{C}$ resulted in a microstructure free from $\delta$-ferrite, with a grain size of $270 \mu \mathrm{m}$.

Specimens for plane strain compression testing were lubricated with Dag 2626 (Acheson Colloids Ltd). The plane strain compression testing machine has been described elsewhere $[1,11]$ and has separate furnaces for reheating specimens and for testing them. Temperatures were checked using dummy specimens drilled to insert a Pyrotenax chromal-alumel thermocouple with the bead at mid-length, mid-breadth and mid-thickness. These were reheated, transferred to the test furnace and tested at constant strain rates in the standard way. Test specimens were preheated to $980{ }^{\circ} \mathrm{C}$, inserted in the test furnace at $950{ }^{\circ} \mathrm{C}$, and held for $180 \mathrm{~s}$ to eliminate temperature gradients before testing at constant equivalent strain rates of $0.05,0.5$ and $5.0 \mathrm{~s}^{-1}$ to an equivalent strain of 1.5 in a single deformation, or with deformation interrupted at a strain of 0.25 . After the interruption, straining was continued at the same strain rate, 
or with an increase of one or two orders of magnitude in strain rate imposed. Changing the clock frequency for recording data at the higher strain rates, and constraints on the ram approach speed for the second deformation meant that a minimum time interval of $15 \mathrm{~s}$ was required between deformations when strain rate was changed. The influence of static recovery in this time interval was investigated by using increased time intervals between deformations. Specimens were water quenched to room temperature after testing.

The Batch 2 steel, used for the type (2) tests, is commercial slab received from Outokumpu Stainless Limited. The analysis is given in Table 1. The as received material again contained $\delta$-ferrite, but this was eliminated by a heat treatment for 2 hours at $1000{ }^{\circ} \mathrm{C}$. Specimens of length, breadth and thickness $60 \times 30 \times 10 \mathrm{~mm}$ were machined for testing in the newer plane strain compression machine [12]. This has a higher speed capability than the older machine, and an induction heating unit for reheating the specimen before robotic transfer into the test furnace. A thermocouple hole $1.5 \mathrm{~mm}$ diameter and $5 \mathrm{~mm}$ deep was drilled into the centre of the $60 \times 10 \mathrm{~mm}$ face of all the specimens for insertion of a Pyrotenax chromal-alumel thermocouple. Dag 2626 was applied to the deformation zone of the specimens as lubricant and was allowed to dry before testing was carried out. All specimens were reheated to $1025^{\circ} \mathrm{C}$ at a heating rate of $10^{\circ} \mathrm{C} / \mathrm{s}$ and soaked for $60 \mathrm{~s}$ before transfer to the test furnace at $1025^{\circ} \mathrm{C}$. Test were carried out at strain rates of $0.5,5.0$ and $50 \mathrm{~s}^{-1}$, with strain rates ramped at constant values of $\mathrm{H}= \pm 2,10$ and 25 to a strain of 1.0 and then continued at constant strain rate to a strain of 1.2. Specimens were then water quenched to room temperature.

\section{Results and Discussion}

The experimental stress - strain curves of Barbosa [13] were reanalysed using the temperature changes computed from a finite difference model [14] to obtain the instantaneous values of $\mathrm{Z}$ to correlate with the flow stress. This contrasts with the original analysis [15], in which the temperature changes due to deformational heating were not considered. The data are still correlated well by the same forms of equations, but with changed coefficients. For the range of $\mathrm{Z}$ of $2 \times 10^{18}$ to $2 \times 10^{20} \mathrm{~s}^{-1}$ (with $\mathrm{Q}_{\mathrm{def}}$ $=460 \mathrm{~kJ} / \mathrm{mol}$.) of interest in the present work, the flow stresses, $\sigma_{0}$, at zero strain, $\sigma_{0.1}$, 
at 0.1 strain, $\sigma_{\mathrm{p}}$ and $\sigma_{\mathrm{ss}}$, the peak and steady state stresses when dynamic recrystallisation takes place, and $\sigma_{\mathrm{e}}$, the (extrapolated) steady state stress for work hardening and dynamic recovery only could all be equally well fitted by the exponential or hyperbolic sign relationships with $\mathrm{Z}$. The more generic hyperbolic sign relationships, which are valid over the whole range of $\mathrm{Z}$ of interest in hot working, are given below.

$$
\begin{aligned}
& \sigma_{0}=65.7 \sinh ^{-1}\left(\mathrm{Z} \times 10^{-17}\right)^{0.077} \\
& \sigma_{0.1}=62.2 \sinh ^{-1}\left(\mathrm{Z} \times 10^{-17}\right)^{0.162} \\
& \sigma_{\mathrm{e}}=123.8 \sinh ^{-1}\left(\mathrm{Z} \times 10^{-17}\right)^{0.206} \\
& \sigma_{\mathrm{ss}}=103.5 \sinh ^{-1}\left(\mathrm{Z} \times 10^{-17}\right)^{0.210}
\end{aligned}
$$

For work hardening and dynamic recovery only, the stress at any strain, $\varepsilon$, is

$$
\sigma^{\prime}=\sigma_{0}+\left(\sigma_{\mathrm{e}}-\sigma_{0}\right)\left[1-\exp \left(-\varepsilon / \varepsilon_{\mathrm{r}}\right)\right]^{0.5}
$$

where $\varepsilon_{\mathrm{r}}$ is a relaxation strain given by

$$
\varepsilon_{\mathrm{r}}=0.1\left[\left(\sigma_{\mathrm{e}}-\sigma_{0}\right) /\left(\sigma_{0.1}-\sigma_{0}\right)\right]^{2}
$$

When dynamic recrystallisation takes place, Equation (7) is only applicable when $\varepsilon<0.7 \varepsilon_{\mathrm{p}}$, where $\varepsilon_{\mathrm{p}}$ is the strain to the peak stress, which depends on the initial grain size, $\mathrm{d}_{0}$, and $\mathrm{Z}$ as

$$
\varepsilon_{\mathrm{p}}=0.473 \mathrm{~d}_{0}{ }^{0.029} \mathrm{Z}^{0.035}
$$

At higher strain, when $\varepsilon \geq 0.7 \varepsilon_{\mathrm{p}}$, the flow stress is

$$
\sigma=\sigma^{\prime}-\left(\sigma_{\mathrm{e}}-\sigma_{\mathrm{ss}}\right)\left\{1-\exp 0.49\left[\left(\varepsilon-0.7 \varepsilon_{\mathrm{p}}\right) /\left(\varepsilon_{\mathrm{ss}(\mathrm{iso})}-0.7 \varepsilon_{\mathrm{p}}\right)\right]^{1.4}\right\}
$$


where the strain to the onset of steady state under isothermal deformation conditions is

$$
\varepsilon_{\mathrm{ss}(\mathrm{iso})}=0.469 \mathrm{Z}^{0.024}
$$

The effect of the temperature rise produced by deformational heating on the stress strain curves for continuous deformation at constant strain rate is illustrated in Fig. 1. The above equations are assumed to be equations of state to obtain the isothermal curves, which show constant steady state stress, as expected for work hardening and dynamic recovery at constant temperature. These equations have been used as equations of state to correct for temperature differences in individual interrupted double deformation tests to the computed value for the strain of the interruption, and to produce the computed stress - strain curves for the ramped changes in strain rate tests.

The experimental strain rate changes in the ramped strain rate tests started closely linear on $\log \dot{\varepsilon}$ versus $\varepsilon$ plots, i.e. at constant $H$, as illustrated in Fig. 2 for strain rates increasing from $5.0 \mathrm{~s}^{-1}$ to $50 \mathrm{~s}^{-1}$ and decreasing from $5.0 \mathrm{~s}^{-1}$ to $0.5 \mathrm{~s}^{-1}$. However, for increasing strain rates, Fig 2(a), the final value of $50 \mathrm{~s}^{-1}$ was not reached immediately at the end of the linear change, particularly at the highest value of $\mathrm{H}$, and the periods of linear change gave values of $\mathrm{H}=+2,+12$, and +36 compared with the control values of $+2,+10$, and +25 . For decreasing strain rate, Fig, 2(b), the final control strain rate was not reached, particularly at the control value of $\mathrm{H}=-2$, and there was some instability in the final strain rate, particularly at the control value of $\mathrm{H}=-25$. The experiments give values of $\mathrm{H}=-2,-20$, and -40 for the control values of $\mathrm{H}=-2$, 10, and -25 . These results show that the test conditions have exceeded the control capabilities of the testing machine, so in analysing the flow stress data, in all cases the experimental values of strain rate versus strain have been used to compute instantaneous values of $Z$.

In the machine used for these tests, the specimens are heated in an induction coil controlled by the thermocouple inserted in the specimen. Before the start of deformation, the thermocouple reading gave $1025{ }^{\circ} \mathrm{C}$ for every test, but when deformation started there were some unexpected changes in the thermocouple 
readings, compared with the normal lag in temperature change below the predicted value until good thermal contact has been made by deformation of the bead [14]. The unexpected changes could have arisen from variable thermal contact during heating, and the relatively short holding time at constant temperature $(60 \mathrm{~s})$ before testing, but had generally been reduced to less than $10{ }^{\circ} \mathrm{C}$ difference from the predicted value at the strain for the start of the strain rate change. Because of the ambiguity, analysis of the flow stress was carried out using instantaneous values of $\mathrm{Z}$ computed both from the predicted temperatures and from the measured temperatures. Generally the differences were small during the strain rate change, as illustrated in Fig. 3(a), with the predicted temperature generally giving closer correspondence between the experimental and computed flow stresses. The exception is shown in Fig. 3(b), when the experimental temperatures clearly give the closer correspondence with the experimental stress - strain curve.

For all the changing strain rate conditions, the stress - strain curves computed from the predicted temperatures are shown in Figs. 4 and 5, in which the stress scales for the different curves have been offset by $50 \mathrm{MPa}$ for clarity. The changing strain rate conditions in Fig. 4 correspond to those given in Fig. 2, whereas those in Fig. 5(a) are for the lower initial strain rate and in Fig.5(b) are for the higher initial strain rate. These curves show some differences between the experimental and computed flow stresses, but the differences do not increase systematically with the rate of change of strain rate and, for example, at the control $\mathrm{H}=-25$ in Fig 5(b), the flow stress closely follows the oscillations in strain rate after the change.

Overall, the results therefore indicate that a mechanical equation of state can be applied without significant error in $\mathrm{FE}$ calculations involving changes in $\mathrm{Z}$ with values of $\mathrm{H}$ in the range +36 to -40 .

The influence of delay time between deformations on the stress - strain curves at constant strain rate in the double deformation tests is illustrated in Fig. 6. This shows that increasing delay time causes a larger drop in the initial flow stress for the second deformation, $\sigma_{0(2)}$, and an increase in the strain interval, $\Delta \varepsilon$, to attain the equation of state value of stress in the second deformation. For a constant delay time of $15 \mathrm{~s}$ between deformations, increasing the strain rate produces similar effects, Fig. 7. 
The effects on initial flow stress are conveniently quantified using the restoration index,

$$
\mathrm{R}=\left(\sigma_{\varepsilon(1)}-\sigma_{0(2)}\right) /\left(\sigma_{\varepsilon(1)}-\sigma_{0(1)}\right)
$$

where $\sigma_{\varepsilon(1)}$ is the stress at the end of the first deformation and $\sigma_{0(1)}$ and $\sigma_{0(2)}$ are the initial flow stresses for the first and second deformations, respectively. The results for all the tests at constant and changing strain rates are shown in Fig. 8, in which $\mathrm{R}$ is plotted against $\log (1+t)$, where $t$ is the time interval between deformations. There is considerable scatter in the data, particularly after changing strain rate, but the results are reasonably fitted by straight lines. When there is no change in strain rate, the line is consistent with the value of $\mathrm{R}=0$, when $\mathrm{t}=0$, as expected when static recovery alone leads to the real values of R. For increasing strain rates, the results are clearly offset to higher values of $\mathrm{R}$ as a result of the dislocation density inherited from the end of the first deformation being lower than for tests at a constant strain rate of the second deformation. From Figs. 6 and 7, it is clear that lower initial flow stress in the second deformation leads to an increase in the strain interval for the transient flow stress to be eliminated and the expected value from the equation of state to be reestablished. The asymptotic approach of the two curves makes estimation of $\Delta \varepsilon$ difficult, but, as shown in Fig. 9, $\Delta \varepsilon$ correlates linearly with $\mathrm{R}$, as $\Delta \varepsilon=0.69 \mathrm{R}$, and appears to be independent of whether the value of $\mathrm{R}$ arises from change in strain rate or increased static recovery between deformations.

It is of interest to compare the present results with the analysis by Barraclough et al [3] of their results for "instantaneous" change in strain rate tests on Type 304 stainless steel. They considered that there should be an upper limit to the rate of change of $\mathrm{Z}$ during deformation for which an equation of state for flow stress would be followed. Using the definition of $\mathrm{H}$ in Equation (1), this limit is given by:

$$
\mathrm{H}_{\mathrm{lim}}=\Delta \log \mathrm{Z} / \Delta \varepsilon
$$

From the present results, extrapolation of the lines in Fig. 8 to $t=0$, to eliminate the effects of static recovery, leads to values of $\mathrm{R} \approx 0.1$ and 0.2 for $\Delta \log \mathrm{Z}=1$ and 2 , 
respectively. From the correlation in Fig. 9, the corresponding values of $\Delta \varepsilon \approx 0.069$ and 0.138 , respectively, giving $\mathrm{H}_{\lim } \approx 14.5$. However, the earlier results for the ramped changes in strain rates, Figs. 4 and 5 , had values of $\mathrm{H}$ up to +36 for increasing strain rate, i.e. about $2.5 \times \mathrm{H}_{\mathrm{lim}}$, without systematic transients in flow stress. It is therefore concluded that the analysis of Barraclough et al [3] was too simplistic, and that the actions of work hardening and dynamic recovery during deformation with ramped changes in strain rate are able to maintain the flow stress at the expected value for an equation of state to high values of $\mathrm{H}$. Conversely, a reduced flow stress at the beginning of a second deformation produced by static recovery, or a change in $\mathrm{Z}$, leads to a significant strain interval with a transient flow stress. The practical consequences of these observations are that in FE modelling of rolling Equations (7) or (10) can be used as equations of state for flow stress during a pass, which starts with a recrystallised microstructure, but when a dislocation structure is inherited from one pass to the next the two pass strains cannot simply be summed, and a correction from Equation (7) must be made.

From the results in Figs 6 and 7, it is apparent that the deviations from the equation of state decrease with strain in a similar manner to the deviation from steady state stress during continuous deformation of specimens with an initial recrystallised structure, Fig.1. For correction of the flow stress in double deformation tests, an equation of the same form as Equation (7) has therefore been fitted, i.e.

$$
\sigma=\sigma_{0(2)}+\left(\sigma^{\prime}-\sigma_{0(2)}\right)\left[1-\exp \left(-\varepsilon_{(2)} / \varepsilon_{\mathrm{r}}^{*}\right)\right]^{0.5}
$$

where $\sigma^{\prime}$ is calculated from Equation (7) for the sum of the strains of the two passes, i.e. $\varepsilon=\varepsilon_{(1)}+\varepsilon_{(2)}, \sigma_{0(2)}$ is the initial flow stress for the second deformation, and $\varepsilon_{\mathrm{r}} *$ is the relaxation strain for the deviation from the equation of state. If it is considered that the experimentally measured strain interval, $\Delta \varepsilon$, represents the strain interval for $95 \%$ of the initial deviation to be eliminated, i.e. when $\varepsilon_{(2)}=\Delta \varepsilon$

$$
\sigma-\sigma_{0(2)}=0.95\left(\sigma^{\prime}-\sigma_{0(2)}\right)
$$

then 


$$
\Delta \varepsilon=2.328 \varepsilon_{\mathrm{r}}^{*}
$$

From the correlation between $\Delta \varepsilon$ and $\mathrm{R}$ in Fig. 9,

$$
\varepsilon_{\mathrm{r}}^{*}=0.296 \mathrm{R}
$$

and from Equation (12)

$$
\sigma_{0(2)}=\sigma_{\varepsilon(1)}^{\prime}-\mathrm{R}\left(\sigma_{\varepsilon(1)}^{\prime}-\sigma^{\prime}{ }_{0(1)}\right)
$$

where $\sigma_{0(1)}^{\prime}$ and $\sigma_{\varepsilon(1)}^{\prime}$ are the computed stresses at the beginning and end of the first deformation, so that in Equation (14) both the magnitude and the duration of the deviation from the equation of state are determined by R. In Fig. 10, stress - strain curves computed from Equation (14) for values of $\mathrm{R}$ typical of the experimental conditions are shown for comparison with the curves in Figs. 6 and 7. It can be seen that the computed curves capture all the essential features and enable allowance for the effects of recovery and of increase in $\mathrm{Z}$ between passes to be made in $\mathrm{FE}$ modelling of rolling, when recrystallisation does not occur between passes.

\section{Conclusions}

From the results of continuous hot deformation tests at constant strain rate, constitutive equations for flow stress of Type 316L stainless steel have been proposed to relate stress to instantaneous values of Zener Hollomon parameter.

Plane strain compression tests with strain rates ramped up or down during deformation to change Zener Hollomon parameter in the range $2 \times 10^{18}$ to $2 \times 10^{20} \mathrm{~s}^{-1}$ at ramping rates of up to 40 orders of magnitude per unit strain showed no systematic deviations in flow stress from the values computed by assuming that the constitutive equations are mechanical equations of state.

Double deformation plane strain compression tests in the same range of Zener Hollomon parameter, with interruption at a strain of 0.25 had a reduced initial flow 
stress for the second deformation as a result of static recovery between deformations. The reduction increased with time and with increase in Zener Hollomon parameter between the two deformations.

For all the tests, the strain interval to re-establish the equation of state value of flow stress in the second deformation increased linearly with the reduction in initial flow stress. A constitutive equation, which accurately quantifies the deviations from the equation of state, is proposed.

\section{Acknowledgements}

The authors are grateful to the UK Engineering and Physical Sciences Research Council - EPSRC (IMMPETUS grant) and to Nippon Steel Corporation for financial support of this research.

\section{References}

[1] J.P. Sah, C.M. Sellars, in C.M. Sellars, G.J. Davies (Eds.), International Conference on Hot Working and Forming Processes, Sheffield, UK, Metals Society (London), 1979, pp $62-66$.

[2] J.J. Urcola, C.M. Sellars, Acta Mater., 35 (1987).2637 - 2647.

[3] D.R. Barraclough, C.M. Sellars, in Mechanical Properties at High Rates of Strain, Inst Physics (London) Conference Series No. 21, 1974, pp 111 - 123.

[4] G.J. Baxter, T. Furu, J.A. Whiteman, C.M. Sellars, Materials Science Forum, $217-222$ (1996) $459-464$.

[5] K. Marthinsen, E. Nes, K. Nord-Varhuang, B. Ronning, in $20^{\text {th }}$ Riso International Symposium on Materials Science, Deformation Induced Microstructures: Analysis and Relation to Properties, Riso National Laboratory, Roskilde, Denmark, 1999, pp405 - 410.

[6] C.M. Sellars, W.J.McG. Tegart, International Metallurgical Reviews, 17 (1972) $1-24$.

[7] C.M. Sellars, A.M. Irrisarri, E.S. Puchi, in E.H. Chia, H.J. McQueen (Eds.), Microstructural Control in Aluminum Alloys, Met. Soc. AIME, Warrendale, Pa., U.S.A., 1986, pp179 - 196.

[8] J-P.A. Immarigeon, J.J. Jonas, Acta Metall., 19 (1971) 1053 - 1061.

[9] R.H. Wagoner, N.M. Wang, Met. Trans., 14A (1983) 2395 - 2405. 
[10] L.P. Karljalainen, M.C. Somani, P.A. Peura, D.A. Porter, in Thermomechanical Processing of Steels, Inst., Materials (London), 2000, pp130 - 139.

[11] C.M. Sellars, in Proc. International Symposium on the Physical Simulation of Welding, Hot Forming and Continuous Casting, Energy, Mines and Resources, Ottawa, Canada, 1992, pp 111.1 - 111.13.

[12] M.S. Loveday, G.J. Mahon, B. Roebuck, A.J. Lacey, E.J. Palmiere, C.M. Sellars, M.R. van der Winden, Materials at High Temperatures, 23 (2006) 85 118.

[13] R.A.N.M. Barbosa, PhD Thesis, University of Sheffield, 1984.

[14] R.J. Hand, S.R. Foster, C.M. Sellars, Mater. Sci. and Technol., 16 (2000) 442 450.

[15] R.A.N.M. Barbosa, C.M, Sellars, in M. Fuentes and J. Gil Sevillano (Eds.), Proc. International Conf. on Recrystallisation and Related Phenomena, Trans Tech Publications, Switzerland, 1992, $461-466$. 


\section{Captions}

Table 1: Composition of the 316L stainless steel used for Batch 1 and 2 testing.

Fig. 1. Experimental equivalent stress - equivalent strain curves at an initial temperature of $950^{\circ} \mathrm{C}$ (broken lines), and curves corrected for isothermal deformation at $950^{\circ} \mathrm{C}$ (solid lines).

Fig. 2. Experimentally observed changes in strain rate with strain for an initial strain rate of $5 \mathrm{~s}^{-1}$ and control values of $\mathrm{H}$ of (a) $+2,+10$ and +25 to $50 \mathrm{~s}^{-1}$, and (b) $-2,-10$ and -25 to $0.5 \mathrm{~s}^{-1}$.

Fig. 3. Comparison of experimental stress - strain curves with those computed from measured and predicted changes in temperature for tests at an initial strain rate of $5 \mathrm{~s}^{-1}$ ramped to $50 \mathrm{~s}^{-1}$ at control values of $\mathrm{H}$ of (a) +2 , and (b) +25 .

Fig. 4. Comparison of experimental stress - strain curves with those computed from predicted changes in temperature for the changing strain rate conditions in Fig. 2. (Note, stress axes shifted by $50 \mathrm{MPa}$ for each set of curves for clarity).

Fig. 5. Comparison of experimental stress - strain curves with those computed from predicted changes in temperature for tests at (a) an initial strain rate of $0.5 \mathrm{~s}^{-1}$ and control values of $\mathrm{H}$ of $+2,+10$ and +25 to $50 \mathrm{~s}^{-1}$, and (b) an initial strain rate of $50 \mathrm{~s}^{-1}$ and control values of $\mathrm{H}$ of $-2,-10$ and -25 to $5 \mathrm{~s}^{-1}$. (Note, stress axes shifted by 50 MPa for each set of curves for clarity).

Fig. 6. Effect of time of interruption on the stress - strain curves for double deformation tests at a constant strain rate of $0.5 \mathrm{~s}^{-1}$. (Note, stress axes shifted by 100 MPa for each set of curves for clarity).

Fig. 7. Effect of change in strain rate on the stress - strain curves in double deformation tests with $15 \mathrm{~s}$ interruption between deformations. (Note, stress axes shifted by $100 \mathrm{MPa}$ for each set of curves for clarity). 
Fig. 8. Dependence of restoration index, R, on time interval between deformations after an initial strain of 0.25 and different changes in strain rate between deformations.

Fig. 9. Correlation between the strain interval, $\Delta \varepsilon$, for stress to reach the equation of state value and the restoration index, $\mathrm{R}$, for various changes in strain rate and time intervals between deformations after an initial strain of 0.25 .

Fig. 10. Computed transients in stress - strain curves for typical values of restoration index R. (Note, stress axes shifted by $100 \mathrm{MPa}$ for each set of curves for clarity). 